\title{
Microcircuitry of the Dark-Adapted Cat Retina: Functional Architecture of the Rod-Cone Network
}

\author{
Robert G. Smith, Michael A. Freed, ${ }^{1}$ and Peter Sterling \\ Department of Anatomy, School of Medicine, University of Pennsylvania, Philadelphia, Pennsylvania 19104
}

The structure of the rod-cone network in the area centralis of cat retina was studied by reconstruction from serial electron micrographs. About 48 rods converge on each cone via gap junctions between the rod spherules and the basal processes of the cone pedicle. One rod diverges to 2.4 cones through these gap junctions, and each cone connects to 8 other cones, also through gap junctions. A static cable model of this network showed that at mesopic intensities, when all rods converging on a cone pedicle are continuously active, the collective rod signal would be efficiently conveyed to the pedicle. At scotopic intensities sufficiently low for only one of the converging rods to receive a single photon within its integration time, the quantal rod signal would be poorly transmitted to the cone pedicle. This is because the tiny signal would be dissipated by the large network into which the individual rod diverges. Under this condition, the rod signal would also be poorly conveyed to the rod spherule. If, however, the rods are electrically disconnected from the network, the quantal signal would be efficiently conveyed to the rod spherule. This analysis suggests that the rod signal is conveyed at mesopic intensities by the cone bipolar pathway and, at scotopic intensities, by the rod bipolar pathway, in accordance with the results of Nelson (1977, 1982; Nelson and Kolb, 1985).

The axon terminals of mammalian rods and cones were observed by Ramón y Cajal (1892) to terminate in contiguity with different types of bipolar neurons. The latter he termed "rod bipolar" and "cone bipolar" neurons, and he believed that they represented private channels for conducting the rod and cone signals directly to ganglion cells. It has been discovered, however, that the axon terminals of rods and cones are interconnected by gap junctions (Kolb, 1977; Raviola and Gilula, 1975) and that a robust rod signal can be recorded in cones and in the neurons postsynaptic to cones, i.e., horizontal cells and cone bipolars (Kolb and Nelson, 1983; Nelson, 1977; Nelson and Kolb, 1983; Steinberg, 1971). Thus, 2 pathways lead the rod signal to the ganglion cell, one via cone bipolars, the other via rod bipolars (Fig. 1). The striking architectural differences between these 2 pathways are described elsewhere (Sterling et al., 1986).

\footnotetext{
Received Feb. 18, 1986; revised Apr. 3, 1986; accepted May 27, 1986.

This work was supported by N.I.H. Grants EY00828 and EY01583 to P.S. and T32EY07035-06 to M.A.F. Throughout this work R.G.S. was supported by N.I.H. Training Grant GM07517. We thank April Firstencel, Jack Megill, and Pat Masarachia for their fine technical help in preparing and analyzing the serial sections, and Suzanne Leahy for preparing the illustrations. We are grateful to Ed Pugh for his thoughtful comments on the manuscript.

Correspondence should be addressed to Robert G. Smith, Department of Anatomy, University of Pennsylvania School of Medicine, Philadelphia, PA 191046058 .

${ }^{1}$ Present address: National Institutes of Health, NINCDS, Bldg. 36, Room 2C02, Bethesda, MD 20205
}

Copyright (C) 1986 Society for Neuroscience $0270-6474 / 86 / 123505-13 \$ 02.00 / 0$
The apparent threshold stimulus intensity for the rod signal in cones and in horizontal cells after prolonged dark adaptation is about 10 quanta $\mu \mathrm{m}^{-2} \mathrm{sec}^{-1}$ on the retina (Nelson, 1977; Steinberg, 1969, 1971), but the threshold for dark-adapted retinal ganglion cells is about $3 \mathrm{log}$ units lower (Barlow and Lcvick, 1969). This suggests that the cone bipolar pathway might carry the rod signal to the ganglion cell at higher intensities and that the rod bipolar pathway might convey the signal at lower intensities. We sought evidence on this question by studying the detailed structure of the synaptic network connecting the rod and cone terminals in the outer plexiform layer in a small patch of the area centralis. The anatomical results were incorporated in to a static cable model of the rod-cone network, and the model was used to analyze the distribution of voltage in the network at different light intensities. The results support the hypothesis that the cone bipolar pathway functions at mesopic intensities, as defined by Enroth-Cugell et al. (1977), and the rod bipolar pathway at scotopic intensities to convey the rod signal to ganglion cells.

\section{Materials and Methods}

\section{Anatomical}

The connections between rods and concs werc studied in the area centralis of an adult cat perfused under pentobarbital anesthesia with a mixture of glutaraldehyde and paraformaldehyde. The tissue was stained en bloc with uranyl acetate, prepared for electron microscopy, cut tangentially into 80 serial, ultrathin sections, and photographed in the electron microscope. The sections had a gold interference color and therefore were taken to be $0.095 \mu \mathrm{m}$ thick (Peachey, 1958). Reconstructions were performed according to methods described by Stevens et al. (1980).

\section{Conceptual basis of the model}

The mammalian rod responds to light with a hyperpolarizing current that corresponds approximately to intracellular voltage changes on the order of a few millivolts to about $100 \mathrm{mV}$ (see Baylor et al., 1984). For the purpose of simulation, we have ignored the sign of this voltage change and discuss our results in terms of the rod "signal," which is always assumed to be hyperpolarized with respect to the depolarized dark voltage.

We wished to determine how the voltage produced in a rod would be partitioned between its own axon terminal ("spherule") and the axon terminals ("pedicles") of neighboring cones to which it is connected by electrical synapses. This partition was studied first at low simulated light intensity where the transductions of individual quanta are separated enough in time and space to prevent their signals from interacting (Ashmore and Falk, 1980). In this condition, current was injected into the rod-cone network at a single point. The partition was also studied at higher intensity, where quanta are transduced simultaneously in all rods. These studies employed a computer model of the rod-cone network based on Rallian cable equations (Rall, 1959). The details of this model are presented in an Appendix to this paper. 


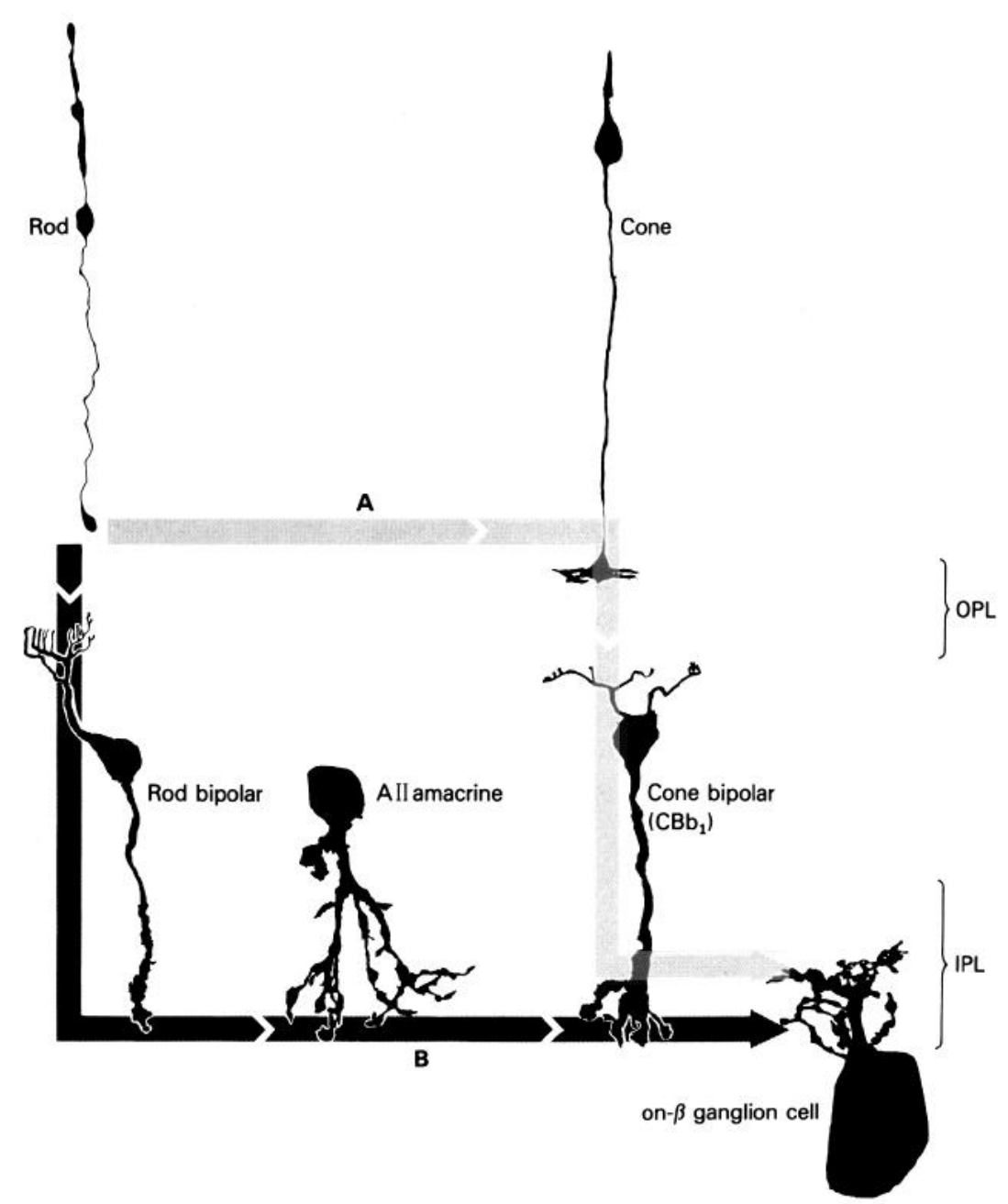

Figure 1. Two rod pathways to the ON-beta ganglion cell. $A$, Cone bipolar pathway. $B$, Rod bipolar pathway.

\section{Results}

\section{Distribution of photoreceptors}

The patch of retina studied was located within the area centralis, about $2^{\circ}$ temporal to its exact center. The cones at the level of the inner segments were fairly widely and regularly spaced (nearest neighbor distance $=5.3 \pm 0.9 \mu \mathrm{m}$ ) and had a density of $23,000 / \mathrm{mm}^{2}$. The rods at this level entirely filled the spaces between the cones and had a density of $463,000 / \mathrm{mm}^{2}$ (Fig. 2). Counts at the level of the outer plexiform layer gave the same densities for the cone pedicles and rod spherules. The geometrical relationships were different, however, because the axon terminals are larger in diameter than the outer and inner segments. The cone pedicles were therefore closely spaced and formed a single tier in the outer plexiform layer that was almost confluent (Fig. 3). The rod spherules accumulated in 3 closely packed tiers overlying the pedicles (Fig. 4) and also filled in the interstices between the pedicles (Fig. 3). The cone and rod densities observed here are in general agreement with previous reports by Steinberg et al. (1973), Holländer and Stone (1972), and Wässle and Riemann (1978).

\section{Morphology and dimensions of photoreceptors}

Cones. The cone soma was about $5 \mu \mathrm{m}$ in diameter and occupied the upper tier of the outer nuclear layer (Kolb, 1977). The cone axon was about $1.5 \mu \mathrm{m}$ in diameter and descended for about $50 \mu \mathrm{m}$ before terminating in the middle of the outer plexiform layer. The distal end of the axon passing through the tiers of rod spherules sometimes bore small gap junctions that contacted the spherules en passage (Fig. $5 A$ ). At this level the axon sometimes emitted fine spicules (Fig. 6) that also formed gap junctions with the spherules. The cone axon swelled just beneath the last tier of rod spherules to form the pedicle, which was filled with vesicles and housed numerous synaptic ribbons and several large mitochondria (Fig. 5B).

Six adjacent cone pedicles were reconstructed in order to determine the number and extent of their basal processes. It can be seen in Figures $5 B$ and 6 that the base of each pedicle formed an irregular polygon from whose corners processes extended laterally for up to $4 \mu \mathrm{m}$. These processes were relatively broad in the tangential plane but were extremely flattened, since they usually occupied no more than the thickness of a single section. In addition to these broad, flat processes, there were fine, cylindrical processes $(0.1 \mu \mathrm{m}$ diameter $)$ projecting from the upper surface of the pedicle and sometimes from the upper surface of the laterally projecting flat processes. These fine processes were observed occasionally to branch and could be followed for up to $2 \mu \mathrm{m}$ in their ascent into the layer of rod spherules. The number of lateral plus ascending processes observed to arise from a cone pedicle was $6-11$, with a mean of 8.2 . Gap junctions with individual rod spherules were identified on both the broad, flat processes and on the ascending, cylindrical ones (Fig. 5C). One to 4 contacts were observed per pedicle, with a mean of 2.4 .

Rods. The rod inner segment is connected to the rod spherule by a fine process $(0.2 \mu \mathrm{m}$ diameter $)$. At some point in its descent to the spherule, this process dilates to form the spherical rod 


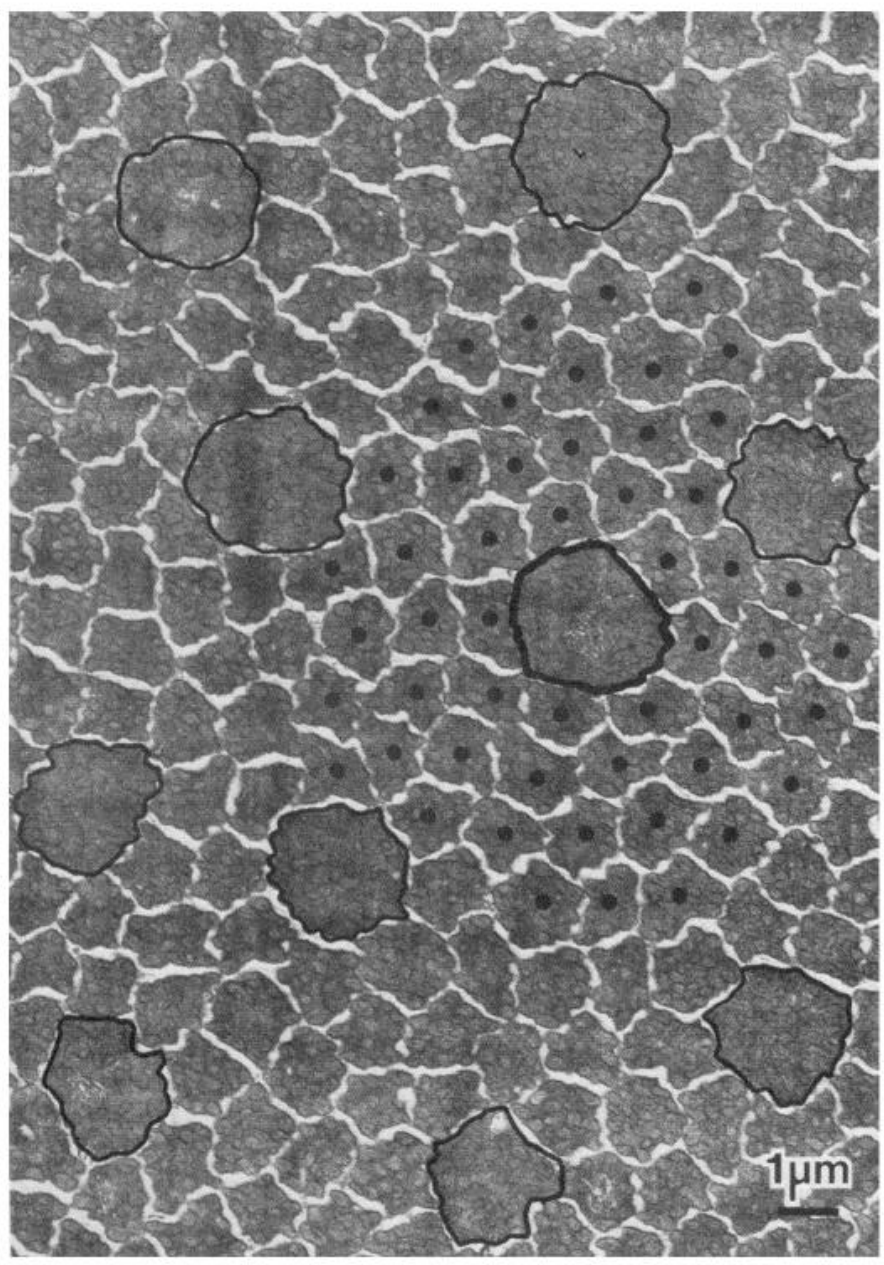

Figure 2. Electron micrograph of tangential section through photoreceptor inner segments. At this level, cones (outlined) are widely separated and the spaces filled by rods. Nine cones (thin outlines) and 48 rods (dotted) are supposed to connect to the central cone (heavy outline) at the level of the outer plexiform layer.

soma ( $3 \mu \mathrm{m}$ diameter), and then reconstricts to form the axon that connects finally to the spherule. The position of the soma along this process varies because the rod somas occupy about 8 tiers in the outer nuclear layer (ONL), but the total distance from the inner segment to the spherule is constant at about 50 $\mu \mathrm{m}$ (Kolb, 1977).

The rod axon dilated to form the spherule, about $3 \mu \mathrm{m}$ diameter, which contained vesicles, 2 synaptic ribbons (Boycott and Kolb, 1973; P. Sterling, R. G. Smith, and M. A. Freed, unpublished observations), and 1 or 2 small mitochondria. The spherule emitted no lateral processes and was almost entirely sheathed by Muller cell processes. At the base of the spherule, the glial processes parted to admit the invaginating processes of horizontal and bipolar cells. It is at this site that the gap junctions have been observed, both in freeze-fracture material (Raviola and Gilula, 1975) and in ultrathin sections (Kolb, 1977; Fig. 5).

\section{Cone pedicle coverage factor and potential connectivity}

We calculated a "coverage factor" (Wässle and Riemann, 1978) for the cone pedicle. This was accomplished by circumscribing each reconstructed pedicle and its basal processes. The mean diameter of the circle was $11.1 \mu \mathrm{m}$ and the mean area was $98.5 \pm$ $24.6 \mu \mathrm{m}^{2}$. This area, multiplied by the cone density $(23,000 /$

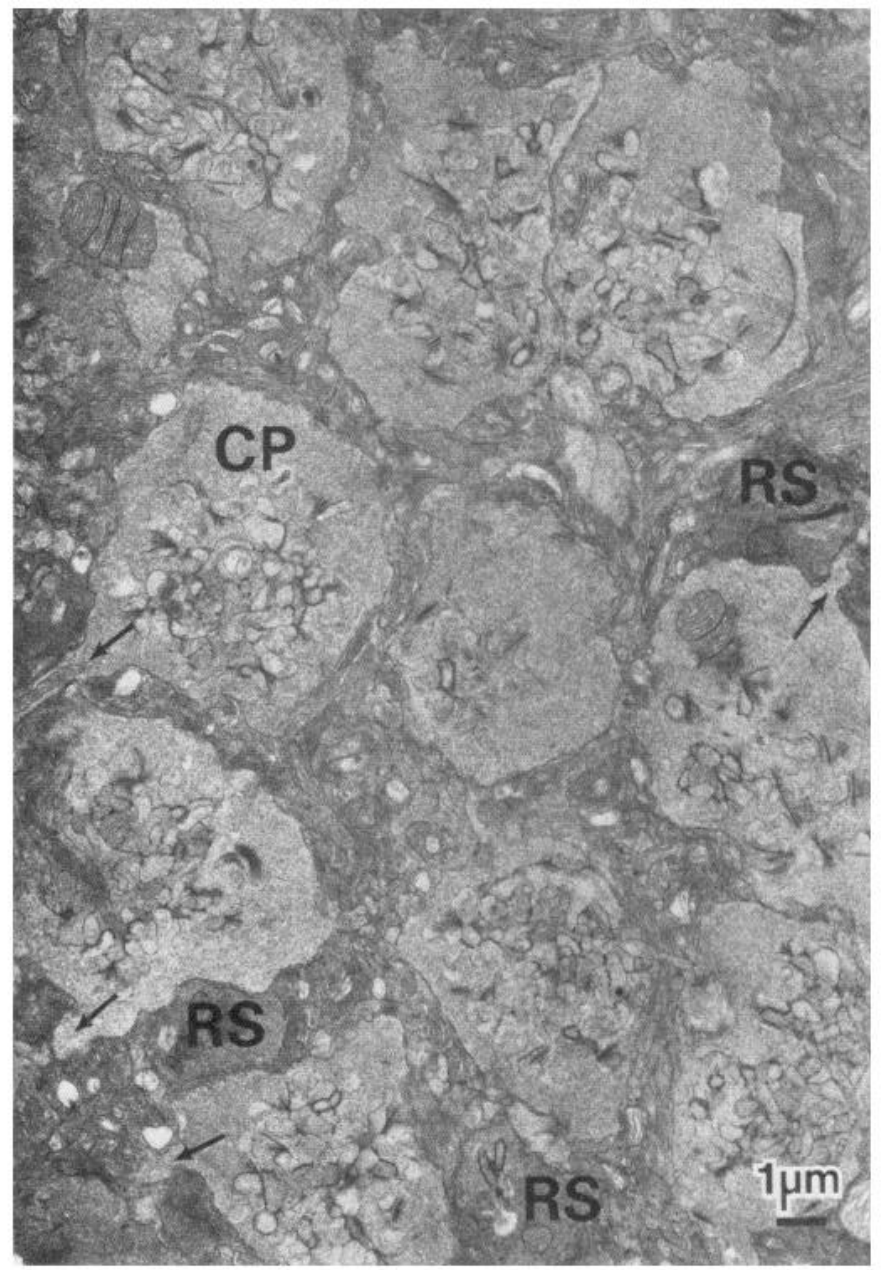

Figure 3. Electron micrograph of tangential section through the level of cone pedicles $(C P)$. Cone pedicles have a larger diameter than cone inner segments; therefore the pedicles are almost adjacent and can form contacts with each other via short basal processes (arrows). Some rod spherules $(R S)$ are present, but these are mainly located in several tiers overlying the cone pedicles (Figs. 4 and 7).

$\mathrm{mm}^{2}$ ), gives a coverage factor of 2.3. The actual coverage might be somewhat greater because the extent of the basal processes may be underestimated by our reconstructions.

With this information, one can estimate the potential divergence and convergence of rod spherules onto cone pedicles. A coverage factor of 2.3 means that every point in the outer plexiform layer is covered by the processes of 2.3 cones. This implies that each rod spherule, considered to be a point in the field of a pedicle, can potentially contact 2.3 cones. The number of rod spherules circumscribed by the field of 1 cone pedicle is 463,000 / $\mathrm{mm}^{2} \times 98.5 \times 10^{-6} \mathrm{~mm}^{2}$, or 45.6 . Thus, about 46 rod spherules potentially converge on each cone pedicle.

\section{Determining the actual connections}

We studied 20 adjacent rod spherules in serial sections in order to count and measure their gap junctions with cone basal processes. Gap junctions were observed on 19 spherules; several spherules had as many as 4 gap junctions, and the mean was $2.4 \pm 1.3$. These junctions, as noted, were clustered at the base of the spherule and were small, about $0.1 \mu \mathrm{m}$ long. They were estimated to extend for $0.2 \mu \mathrm{m}$, about twice the thickness of 1 section. The junctional area was measured as about $0.021 \pm$ $0.011 \mu \mathrm{m}^{2}$. Gap junctions of this size could easily be missed if 


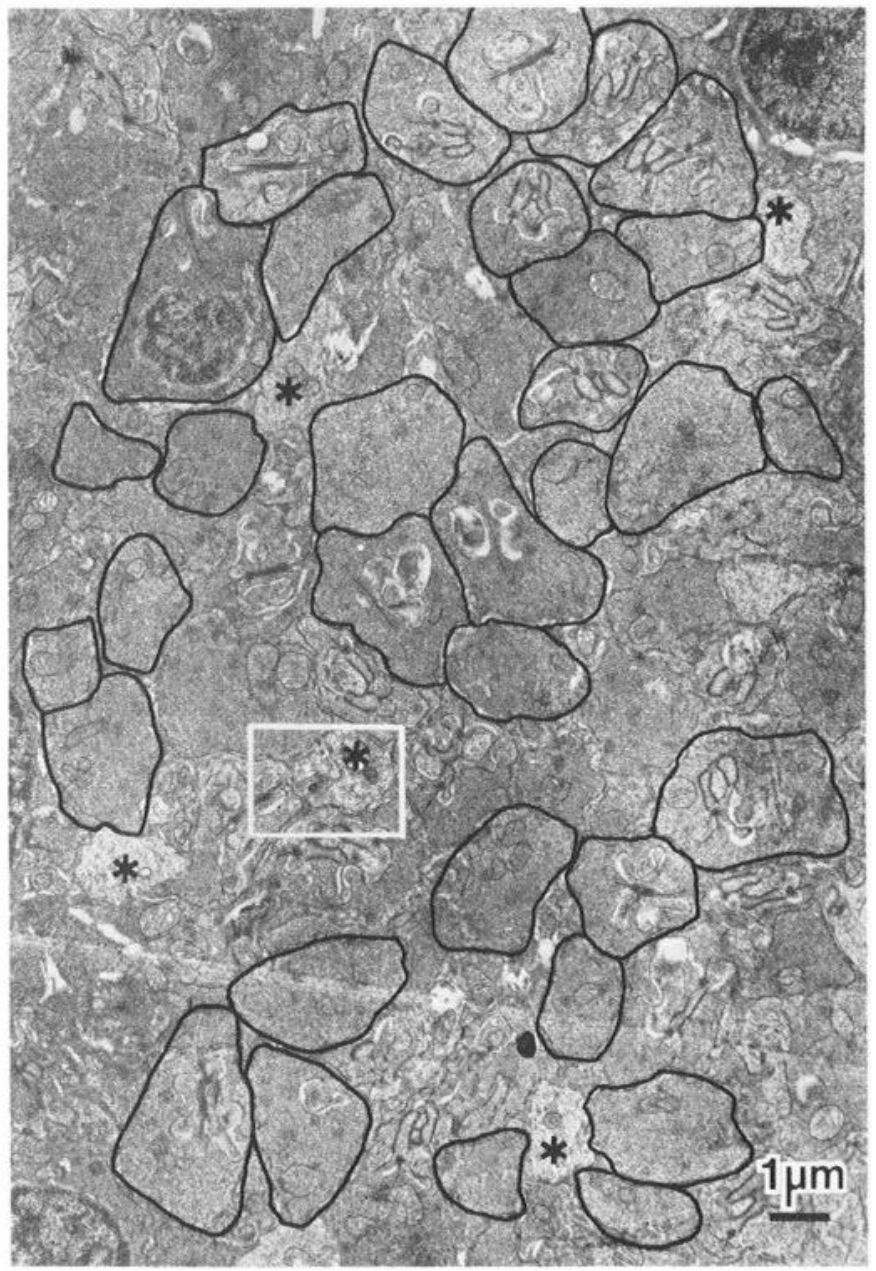

Figure 4. Electron micrograph of tangential section through layer of rod spherules (outlined) just above the cone pedicles. Descending cone axons (*) contact the spherules en passage. Outlined axon is shown at higher magnification in Figure $5 \mathrm{~A}$.

they were photographed en face; therefore, the present counts must be considered a minimum estimate.

Each of the 2.4 gap junctions on a rod spherule probably belonged to a different cone, because we never observed a basal process to make more than 1 contact on a spherule. If this is so, then it would appear that each spherule actually diverged to 2.4 cones. This is gratifyingly close to the potential divergence (2.3) calculated above from entirely different measurements. Furthermore, since the ratio of rod-cone densities is about 20 , and each rod contacts on average 2.4 cones, the actual number of rods contacting a cone pedicle must be about 48 (M. A. Freed, unpublished observations). Again, this is close to the potential convergence (45.6) calculated above from a different set of measurements.

\section{Connections between cones}

Gap junctions between cones have been reported (Kolb, 1977; Raviola and Gilula, 1975), and we have observed them as well in the present material (Fig. $5 D$ ). They were $0.014 \pm 0.006 \mu \mathrm{m}^{2}$ in area and were mostly observed between the fine basal processes. In a few instances we observed contacts between pairs of the 6 reconstructed pedicles (Fig. 6), but it was impossible to assign most of the cone-cone junctions observed in the neuropil to a particular pedicle. Instead, we counted the cone-cone junctions present in each of the 6 pedicle fields and found 2-9 junctions, with a mean of 5.3. We suspect that this is an un- derestimate because of the likelihood that some of these junctions, which were very small, were missed when photographed obliquely or en face. Each cone pedicle has the potential to contact 8.9 other pedicles whose fields overlap or abut its field (P. Sterling, unpublished observations). The simplest interpretation of these observations is that each cone pedicle contacts, with a single gap junction, most and possibly all of the other pedicles with which it has the potential to do so. Figure 7 summarizes the 3-dimensional organization of the photoreceptors described here.

\section{Static cable model}

To study the partition of voltage between rod and cone terminals, we used the static model of a passive electrical network, described in the Appendix. We simulated 3 different conditions: in the first, all rods simultaneously received multiple photons; in the second, only 1 rod received 1 photon; and in the third, 1 rod received a photon, but the rod-cone gap junctions were nonconducting (Fig. 8). The resistances of somas and terminals were calculated from their surface areas, and the spread of current along their processes was calculated using standard parameters $\left(R m=5000 \Omega \mathrm{cm}^{2}\right.$ and $R i=100 \Omega \mathrm{cm}$; Jack et al., 1983). Some authors have suggested that membrane resistance in retinal neurons may be as high as $10,000 \Omega \mathrm{cm}^{2}$ (e.g., Coleman and Miller, 1984; Fain and Lisman, 1981; Schwartz, 1976). We verified our conclusions using a range of values $(2500-10,000$ $\Omega \mathrm{cm}^{2}$ ) for membrane resistance. Gap junction resistance was nominally taken to be $5 \times 10^{6} \Omega \mu \mathrm{m}^{2}$ (see Appendix), but was given a range of $5 \times 10^{5}$ to $5 \times 10^{7} \Omega \mu \mathrm{m}^{2}$. For the purposes of the model we took the resistance of a nonconducting junction to be 1000 times the conducting resistance.

When all rods were active simultaneously, the calculated voltage transfer from each rod soma to its own spherule was $69 \%$ (Fig. 9, top). The transfer to adjacent cone pedicles was only slightly less, $67 \%$. For different values of $R m$, gap junction resistance, and rod-cone connectivity, the voltage transfers differed somewhat, but not greatly (Table 1). We conclude that when all rods are active, the network of electrical synapses can effectively convey the collective rod signal to the cone pedicles.

When only 1 rod was activated by a single photon, the network behaved quite differently. The voltage transfer from the rod soma to its own spherule was $11 \%$, and to neighboring cone pedicles it was only $0.24 \%$ (Fig. 9 , center). Thus, when only 1 rod is active, the signal tends to be dissipated into the network, and very little of it is present at cone terminals. Essentially the same result was obtained using different values of $R m$, gap junction resistance, and rod-cone connectivity (Table 1).

We also calculated under this condition the voltage transfer from the rod soma to the spherule, assuming that the gap junctions were nonconducting. In this case, the voltage transfer from rod soma to the spherule was $86 \%$ (Fig. 9, bottom) and this effect was insensitive to different values of $\mathrm{Rm}$ (Table 1). Thus the effect of rendering the gap junctions nonconducting is to reduce current spread from the rod terminal, thereby enhancing the voltage available for controlling transmitter release at the chemical synapse onto the rod bipolar.

\section{Discussion}

\section{Intensity ranges covered by cone bipolar and rod bipolar pathways}

The cat retinal ganglion cell responds to rod signals over more than $5 \log$ units of intensity (reviewed by Shapley and EnrothCugell, 1984). Two neuroanatomical pathways connect rods to the ganglion cell (Fig. 1), and the main question addressed by this paper is how responsibility for the full intensity range is apportioned to these 2 pathways. A robust rod signal is recorded in cones and in horizontal cell bodies that receive direct input from cones but lack direct input from rods. The apparent thresh- 

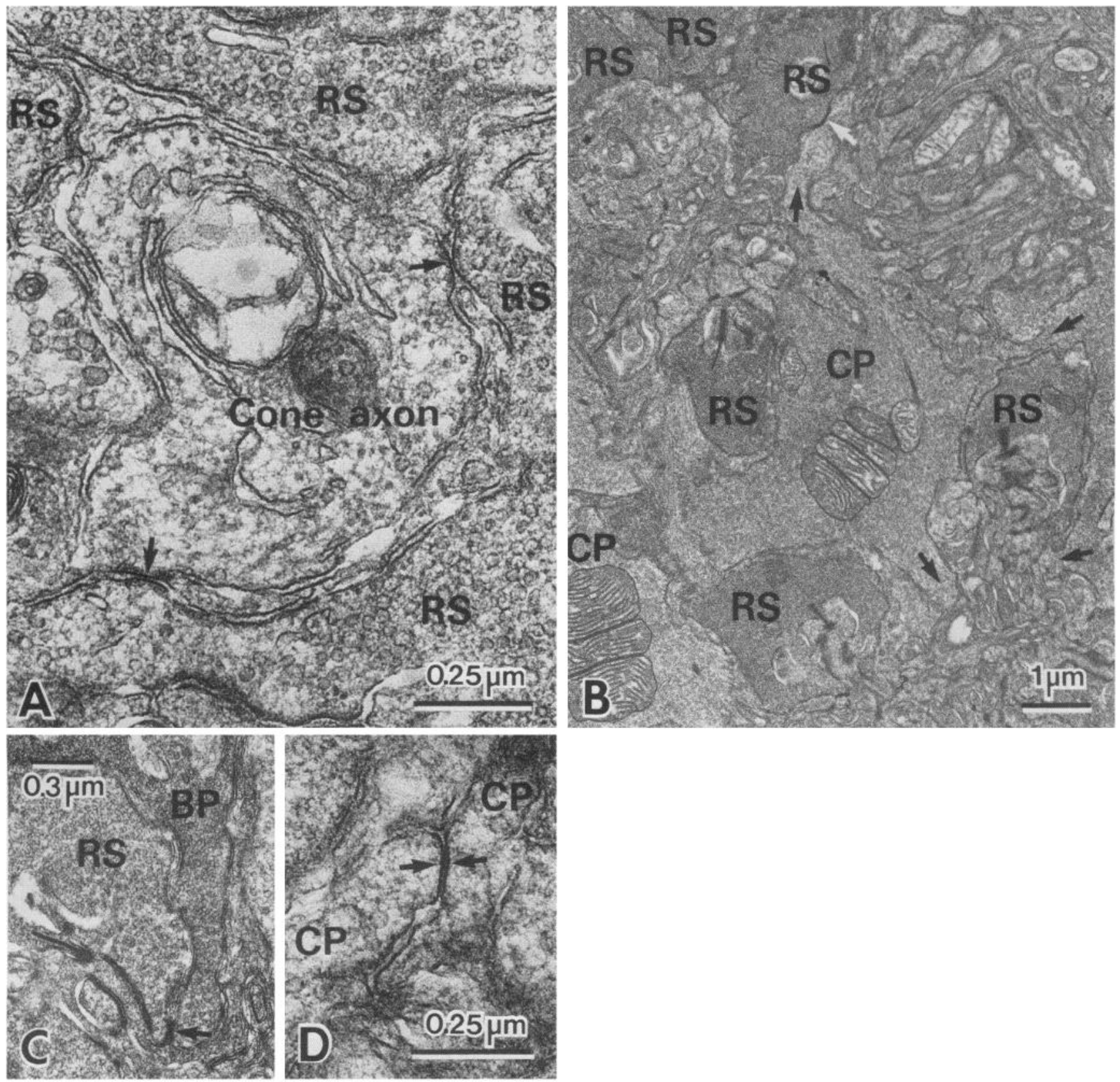

Figure 5. Electron micrographs of tangential sections. A, Cone axon with en passage gap junction contacts (arrows) with rod spherules (RS). Note the retraction of glial processes at these sites. $B$, Cone pedicle $(C P)$ with basal processes (black arrows) and gap junction contact (white arrow) with rod spherule $(R S)$. $C$, Gap junction between cone basal process $(B P)$ and rod spherule $(R S)$. Note that the contact is at the base of the spherule at the site of the invagination. $D$, Cone-cone gap junction between 2 basal processes.

old for this rod signal in cones and horizontal cells is about 10 quanta $\mu \mathrm{m}^{-2} \mathrm{sec}^{-1}$ at the retina, according to Nelson's (1977) in vitro recordings. Steinberg (1969) gives $-0.5 \mathrm{log}$ td scotopic for the apparent rod threshold in horizontal cells in vivo after 1-2 hr of adaptation to total darkness. This value converts to about 3 quanta $\mu \mathrm{m}^{-2} \mathrm{sec}^{-1}$ at the retina (see Shapley and Enroth-Cugell, 1984), approximately the same figure as Nelson's (1977). These results suggest that the pathways leading from cones carry very little rod signal at environmental intensities below 10 quanta $\mu \mathrm{m}^{-2} \mathrm{sec}^{-1}$ at the retina, which corresponds to the low end of the mesopic range defined by Enroth-Cugell et al. (1977).

In contrast, the AII and A17 amacrine cells studied in vitro by Nelson (1982; Nelson and Kolb, 1985) show rod signals at intensities as low as 0.5 quanta $\mu \mathrm{m}^{-2} \mathrm{sec}^{-1}$, which is well into the scotopic range (Enroth-Cugell et al., 1977). Responses to individual quanta were not observed in these cells, but the experiments were not conducted at the lowest scotopic intensities that would be required to reveal them. The AII and A17 amacrine cells receive many synapses from the rod bipolar neuron (M. A. Freed, unpublished observations; Kolb and Famiglietti, 1974; Kolb and Nelson, 1983; Sterling, 1983); therefore it is plausible that pathways leading from the rod bipolar might carry the rod signal over the scotopic range of intensities (Sterling, 1983).

The implication of Nelson's experiments, that the rod signal is conveyed by the cone bipolar pathway over the mesopic range and by the rod bipolar pathway over the scotopic range, is supported by the present study of the rod-cone network. Our 


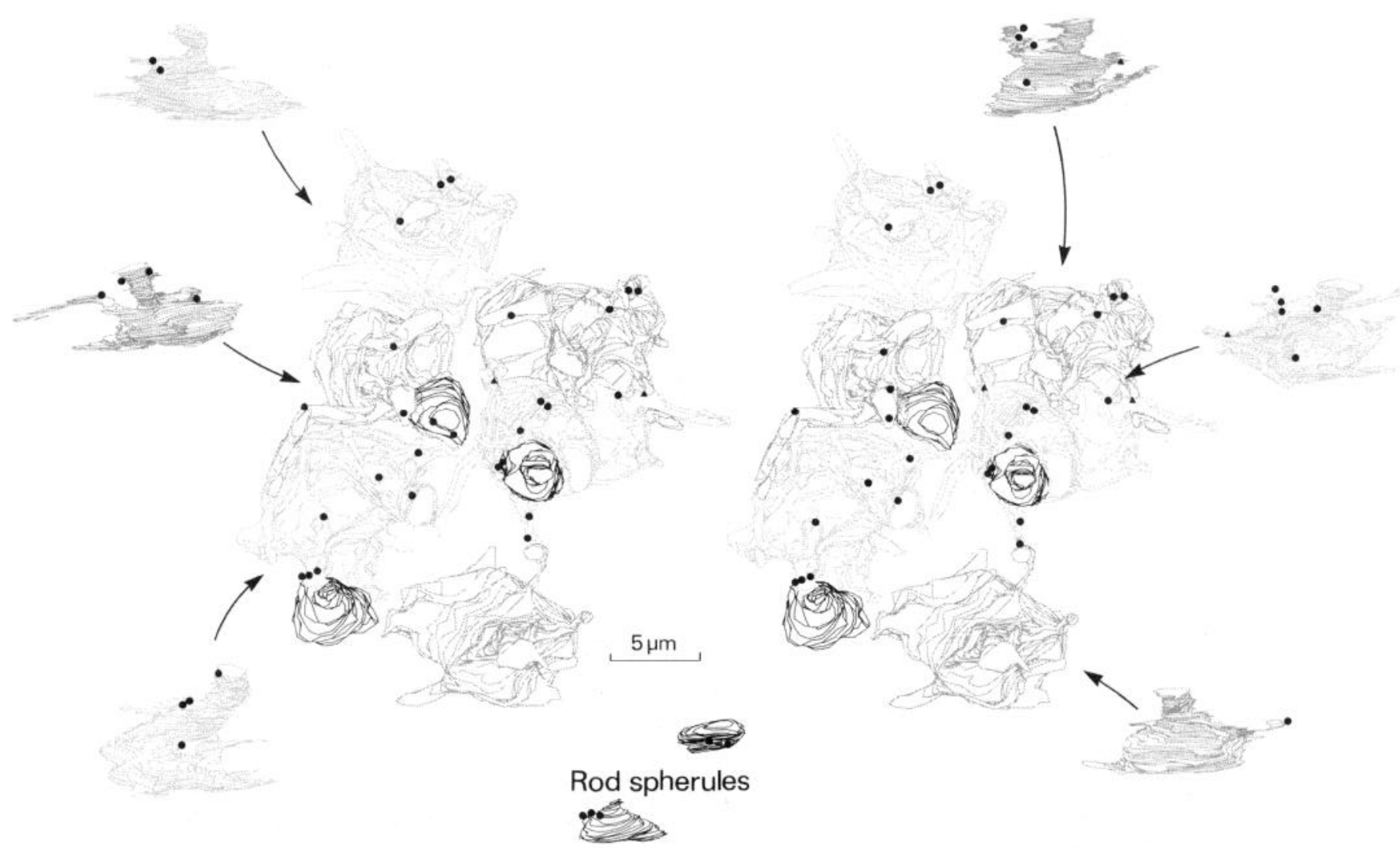

Figure 6. Reconstruction taken from tangential series through the outer plexiform layer, showing details of cone basal processes and location of gap junctions. Six adjacent cone pedicles and 3 rod spherules are shown. The central part of the figure is a stereo pair, which gives a realistic view of the fine basal processes emanating from the cone pedicles. Figures around the edge represent the 6 cone and 3 rod terminals at a slightly higher magnification, rotated to show the fine basal processes without stereo.

main anatomical findings are that many (48) rods converge on each cone and that 1 rod diverges to a few cones (2.4), which, in turn, diverge to other cones (8.9). These connections are established by small gap junctions previously described (Kolb, 1977; Raviola and Gilula, 1975) between the rod spherule and fine basal processes of the cone pedicle. The patterns of convergence and divergence observed here in tangential sections through the area centralis have been confirmed in a series of radial sections in a different retina (P. Sterling, R. G. Smith, and M. A. Freed, unpublished observations). It is to be expected that the exact numbers for convergence and divergence will vary with eccentricity; however, since at all eccentricities rods greatly outnumber cones, the essential features of the network (convergence of many rods onto each cone and divergence of each rod into a large network) are likely to hold.

The cable model based on this anatomy indicates that the rod signal would be efficiently transferred to cones at mesopic intensities. The reason is that, in the mesopic range, all rods collect and temporally sum more than 1 photoisomerization $\left(\mathrm{R}^{*}\right)$ per

\footnotetext{
${ }^{2}$ This conclusion is based on the following calculation: $5 \times 10^{5}$ quanta $\mathrm{deg}^{-2}$ $\mathrm{sec}^{-1}$ at the cornea is given by Enroth-Cugell et al. (1977) as the low end of the mesopic. This corresponds to roughly 10 quanta $\mu \mathrm{m}^{-2} \mathrm{sec}^{-1}$ at the retina. The cross-sectional area of a rod is $2.27 \mu \mathrm{m}^{2}$ (Nelson, 1977); the fraction of photons at retina that is absorbed is taken to be 0.33 (Bonds and MacLeod, 1974); and the efficiency of rhodopsin isomerization by absorbed photons is taken to be about 0.5 (Baylor et al., 1979). Therefore,
}

No. of photons collected/rod/rod integration time

$=10$ photon incident $\mu \mathrm{m}^{-2} \mathrm{sec}^{-1} \times 2.27 \mu \mathrm{m}^{2} \mathrm{rod}^{-1}$

$\times 0.33$ photon absorbed/incident $\times 0.5 R^{*} /$ absorption

$\times 0.25 \mathrm{sec} /$ integration time

$=0.93 R^{*} \mathrm{rod} / \mathrm{rod}$ integration time. rod integration time. ${ }^{2}$ With all rods active, the rod-cone network is relatively isopotential (see Attwell et al., 1984; Schwartz, 1976); therefore, there is little tendency for the signals from individual rods to be dissipated into the network. The rod signal is robust in the cone at mesopic intensities because (1) the signals from temporally summed photoisomerizations in individual rods are large; (2) the signals from many active rods converge on each pedicle; and (3) the signal is efficiently transferred.

The cable model indicates that the rod signal would be inefficiently transferred to cones at scotopic intensities. The reason is that in the scotopic range there is less than 1 photoisomerization/rod per rod integration time. With some rods inactive, the rod-cone network cannot be isopotential and the signal from individual rods tends to be dissipated into the network. As intensity declines in the scotopic range, the rod signal becomes progressively weaker in the cone because (1) the signals in individual rods are small (quantal); (2) the number of active rods converging their signals on the pedicle declines; and (3) efficiency of signal transfer between rod and cone declines as the network becomes progressively less isopotential. For technical reasons (see Appendix), the model permitted only the calculation of the efficiency of signal transfer for the lower scotopic range (below 0.2 quanta $\left.\mu \mathrm{m}^{-2} \mathrm{sec}^{-1}\right),{ }^{3}$ where only 1 of the 48 rods converging on a cone has a single quantal event per integration time. Nevertheless it is clear that the rod signal in cones must begin to deteriorate well above this level, in the high scotopic range.

\footnotetext{
${ }^{3}$ The quantity 0.22 quanta $\mu \mathrm{m}^{-2} \mathrm{sec}^{-1}$ was calculated in the following manner: $R^{*} / 48$ rods/rod integration time $\times 10$ quanta $\mu \mathrm{m}^{-2} \mathrm{sec}^{-1} / 0.93 R^{*} / \mathrm{rod} / \mathrm{rod}$ integration time $=0.22$ quanta $\mu \mathrm{m}^{-2} \mathrm{sec}^{-1}$.
} 


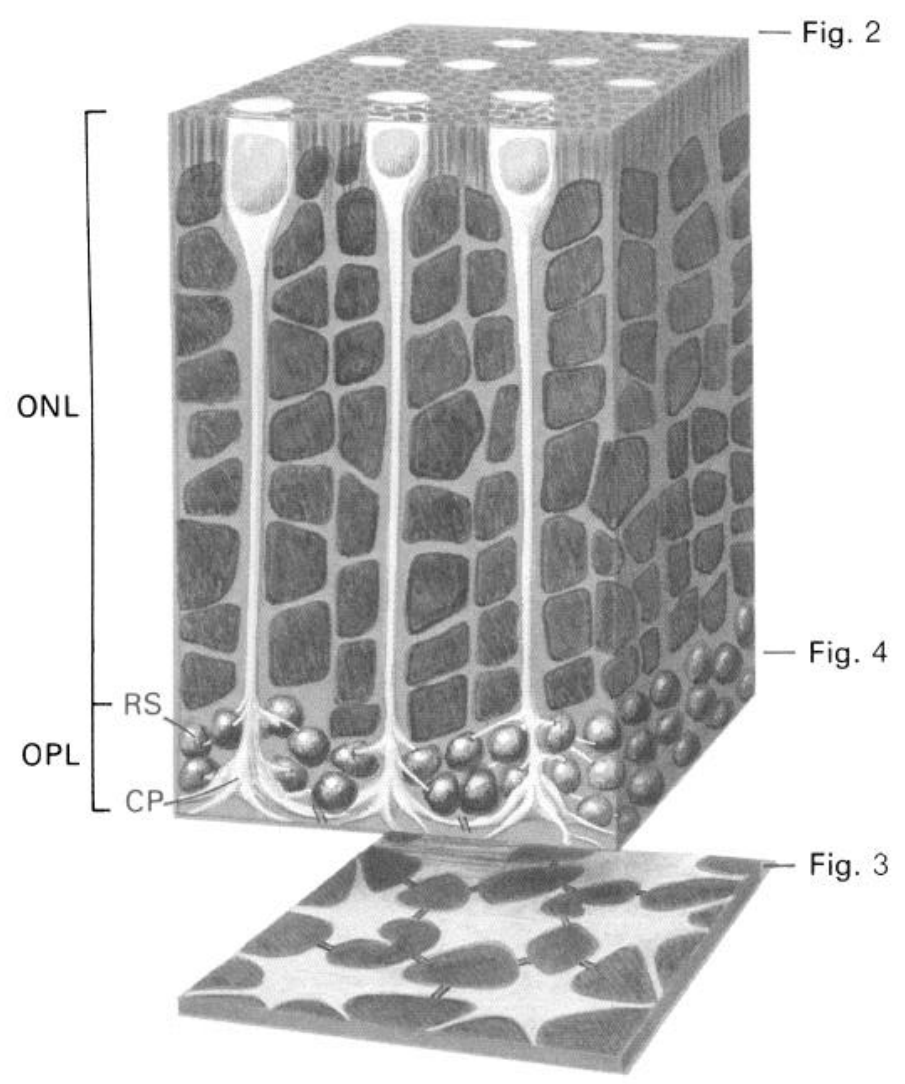

Figure 7. Summary of the photoreceptor organization from the inner segments (top) to the outer plexiform layer (OPL) (bottom). Cone axons descend through the outer nuclear layer past 8 tiers of rod somas and 3 tiers of rod spherules $(R S)$ to form pedicles $(C P)$ that are adjacent and almost confluent. Fine basal processes radiate from pedicles to form gap junctions with other pedicles and the rod spherules above. Rod axons are very fine $(0.2 \mu \mathrm{m}$; not shown). The level of section for Figures $2-4$ is shown on the right.

\section{Modulation of the gap junctions}

The scotopic intensity at which only 1 rod in 48 carries a single quantal event per rod integration time also apparently poses a problem for the rod bipolar pathway. The problem is that divergence of the quantal signal from 1 active rod into the network through gap junctions would tend to dissipate the signal from the rod spherule, where it is needed to modulate release of transmitter onto the rod bipolar. This is indicated clearly by the modeling result that, under this condition, only $11 \%$ of the already small quantal voltage at the rod outer segment is transferred to the spherule. We have no direct evidence as to how this problem is actually solved in the retina, but the model indicates that if the gap junctions were nonconducting under this condition, signal transfer to the rod spherule would be dramatically enhanced $(86 \%)$. Thus, isolating the quantal signals of individual rods by rendering the gap junction nonconducting would be one way to enhance synaptic transmission at the rodrod bipolar junction.

There would be another advantage to isolating the rods at scotopic intensities by shutting down the gap junctions. At high light intensities, the dominant source of noise in the rods is quantum fluctuation, and this is proportional to the square root of the intensity (Rose, 1948; Shapley and Enroth-Cugell, 1984). In this condition, where noise is related to light intensity, there would be no penalty for pooling the voltages of many rods in the cone pedicle rather than pooling them at a later stage. However, at the lower scotopic intensities, where photons are sparse
Table 1. Results of rod-cone modeling ${ }^{a}$

\begin{tabular}{llll} 
Parameter varied & Condition & $\begin{array}{l}\text { Rod } \\
\text { spherule } \\
(\%)\end{array}$ & $\begin{array}{l}\text { Cone } \\
\text { pedicle } \\
(\%)\end{array}$ \\
\hline$R m=2500$ & Twilight & 60 & 57 \\
& Starlight & 11 & 0.23 \\
GJs closed & & 76 & \\
& Twilight & 69 & 67 \\
& Starlight & 11 & 0.24 \\
$R m=5000$ & GJs closed & 86 & \\
& Twilight & 75 & 73 \\
& Starlight & 12 & 0.25 \\
Twenty rods $\rightarrow$ cone, & GJs closed & 92 & \\
$\begin{array}{l}\text { One rod } \rightarrow 2 \text { cones, } \\
\text { One cone } \rightarrow 3 \text { cones }\end{array}$ & Swilight & 57 & 54 \\
Gap junction resistance & Twilight & 17 & 0.17 \\
$\begin{array}{l}\text { decreased } \text { by a factor } \\
\text { of } 10\end{array}$ & Starlight & 59 & 57 \\
Gap junction resistance & Twilight & 7.7 & 0.11 \\
increased by a factor & Starlight & 35 & 74 \\
of 10 & & & \\
\hline
\end{tabular}

Standard parameter values used for model: $R m=5000 ; R i=100 ; 48$ rods cone; 1 rod $\rightarrow 3$ cones; 1 cone $\rightarrow 7$ cones; gap junction resistance $=5 \times 10^{6} \Omega$ $\mu \mathrm{m}^{2}$.

${ }^{a}$ Voltages found in rod-cone circuit as percentages of voltage in rod soma.

${ }^{b}$ Gap junctions.

in time and space, the dominant source of noise is not quantum fluctuation, but rather the continuous dark noise in the rod outer segment (Baylor et al., 1980). In this case, pooling many rods would cause little increase in rod signal because photons are sparse, whereas the noise would increase as the square root of the number of rods converging, and would overpower the fragile rod signal (Ashmore and Copenhagen, 1983; Baylor et al., 1984; Schwartz, 1977). This consideration has led to the suggestion that the quantal signal in a mammalian rod must be subjected to some form of thresholding or filtering before it is pooled with the signals of other rods (Baylor et al., 1984; Hagins et al., 1970). This is an additional reason for believing that, although the rod signals are pooled in the cone pedicle at high intensity, they are probably isolated in the rod spherule at low intensity.

That the rod-cone gap junctions might be rendered nonconducting during the process of dark adaptation seems plausible in view of evidence that gap junctions between horizontal cells in turtle and fish retina can be modulated by neural transmitters (Lasater and Dowling, 1985; Piccolino et al., 1984; Teranishi et al., 1984) and that rod-rod gap junctions in salamander retina can be voltage-sensitive (Stern and MacLeish, 1985). If, in the present case, the rod-cone gap junctions were modulated, one would want to identify the molecular mechanism, the signal controlling it, and the cell type that conveys the signal. To speculate on the molecular mechanism would be pointless; but a plausible candidate for a controlling signal might be one that follows the prolonged time course of dark adaptation.

The "rod aftereffect" has this property. The rod aftereffect is the prolonged hyperpolarization evoked in rods by bright light. After exposure to saturating stimuli, the rod aftereffect takes an hour or more to decay (Penn and Hagins, 1972; Steinberg, 1969). Thus, it is a rod signal that is present in daylight and decays with a time course that corresponds in Nature to the transition from daylight to the low end of the mesopic. Possibly, then, the rod-cone gap junctions conduct while the rods slowly depolarize during dark adaptation, and then become nonconducting when 

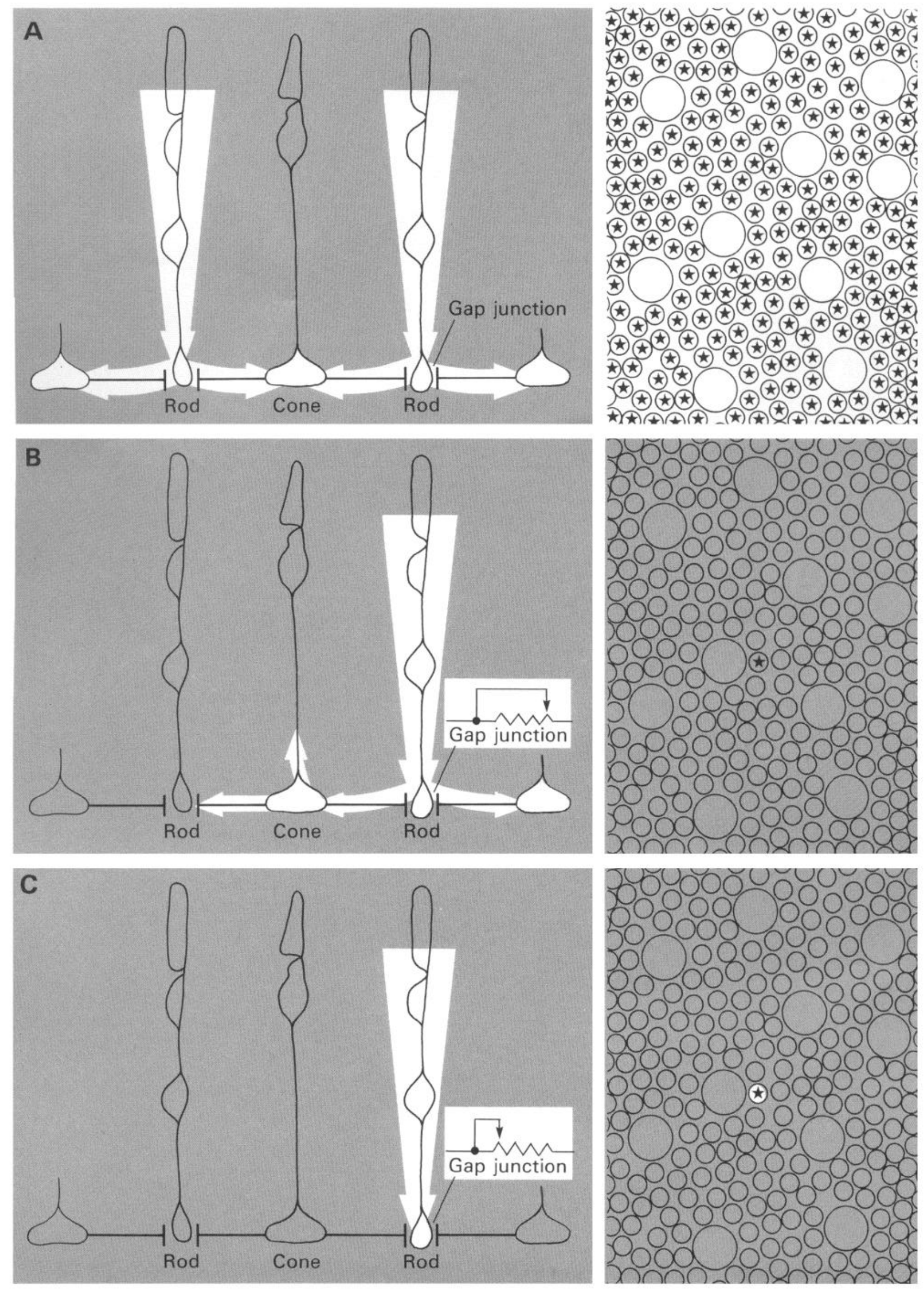
the rods' membrane potential reaches its basal dark level. If the rod aftereffect does control the rod-cone junction, it could be conveyed to an effector mechanism at the molecular level either from within the rod or cone terminals themselves or via synaptic actions of the type A or B horizontal cell dendrites or the type B horizontal cell axon terminal, since all of these structures exhibit the rod aftereffect (Nelson, 1977; Steinberg and Schmidt, 1970).

\section{Appendix}

Rallian cable equations (Rall, 1959) were chosen as the basis for the model because these accurately represent the passive decrementing properties of fine processes such as the rod and cone axons. We chose a static model for simplicity, which seemed justified by the low frequencies present in the rod quantal signal (Baylor et al., 1984). We assumed that all cable membrane conductances were independent of membrane voltage.

Other types of model have been used for similar work, such as the Bessel function technique combined with the square grid approach (e.g., Detwiler and Hodgkin, 1979; Lamb and Simon, 1976; Piccolino et al., 1984; Schwartz, 1976) but were judged to be less appropriate for our purpose. The Bessel function approach makes the simplifying assumption that the cellular network can be approximated using "sheet" conductances to describe a continuous layer of interconnected cells. Input to the sheet is supplied from a point source of current. These assumptions generate a circularly symmetric function to describe the voltage attenuation at different radii in the network. However, this approach cannot estimate the voltage at the central cell in such a network, because the assumption of a point current source means that the Bessel function is undefined at 0 radius. The square-grid approach has been used to give an estimate for the input resistance of such a network by approximating it with discrete resistors and solving using Ohm's and Kirchoff's laws. This gives an approximate estimate of input resistances in a large network, given rough estimates of cell conductance and coupling, but does not provide a way to correlate them with morphological features such as fine axons or basal processes. Thus, the cable equations seemed most relevant for our question, which was concerned with the input resistance of cells at the center of a large network rather than with the voltage attenuation at large distances from the central element.

\section{Tree model using cable equations}

We cast our model as a large array of rods and cones interconnected in the form of a tree. The tree structure represented only the passive electrical properties of the rod-cone network and gave no direct representation of a cell's spatial extent or location. The tree had a starting point (the "root"), which was connected to "descendant branches," each of which had a parent branch and either several, one, or no descendants. Each branch represented a specific anatomical part of a cell, such as soma, axon, terminal, basal process, or gap junction. Axons and dendritic processes were represented as cables having exponential voltage decay along their length. Somas and axon terminals were represented as isopotential regions having a conductance to ground defined by the membrane resistance. Gap junctions were represented as linear-series resistances.

Using Rall's (1959) static cable model, we derived a set of cable equations for describing input resistances and voltage ratios in a tree of cable segments. The input resistance for any branch of the tree network was calculated in the following manner. Each branch (the parent branch) was represented as a cable segment with a resistor connected from its distal end to ground. The resistor represented the parallel combination of the descendants' input resistances. The value for the resistor was calculated only after recursively finding all the descendants' input resistances. Once the value of the distal grounded resistor was found, the value of the input resistance of the parent branch could be calculated. The following derivations show how any value of the distal resistor can be represented as an extension onto the parent cable segment. The extension has the same diameter as the parent and may be either open or closed at its distal end.

The standard cable equation describing the voltage along an infinite cable is

$$
V=\operatorname{Io~ri~} L e^{-x / L}
$$

where $x=$ distance along cable, $I o=$ current injected into the cable, $L=$ lambda $=(\mathrm{rm} / \mathrm{ri})^{1 / 2}, \mathrm{ri}=$ axial resistance per unit length, and $\mathrm{rm}=$ membrane resistance per unit length. Dividing by the input current $I O$, we get the input resistance of an infinite cable at $x=0$ :

$$
R_{\text {inf }}=\text { ri } L
$$

where $r i=$ axial resistance per unit length, and $L=$ lambda $=(r \mathrm{~m} / \mathrm{ri})^{1 / 2}$.

The standard cable equation for the voltage along a closed-end cable segment is

$$
V_{c}=\operatorname{Iori} L\left(\frac{e^{x / L}+e^{-x / L}}{e^{L / L}-e^{-L e / L}}\right)
$$

where $x=$ distance along cable, $L e=$ length of cable segment, $r i=$ axial resistance per unit length, $L=$ lambda $=(r m / r i)^{1 / 2}$, and $I o=$ current injected into cable. Dividing by $I o$, we get input resistance $R e$ of a closed-ended dendrite as a function of length $x$ :

$$
R e=R c=r i L\left(\frac{e^{x / L}+e^{-x / L}}{e^{x / L}-e^{-x / L}}\right)
$$

where $x=$ length of cable segment, $r i=$ axial resistance per unit length, $L=$ lambda $=(\mathrm{rm} / \mathrm{ri})^{1 / 2}$, and $\mathrm{rm}=$ membrance resistance per unit length. We solve for length $x$ :

$$
X e=X c=\frac{L}{2} \ln \left(\frac{R c+r i \times L}{R c-r i \times L}\right)
$$

In equation (5), $\mathrm{Xe}$ represents the length of a closed cable segment that would have an input resistance of $R e$, defined by its diameter and membrane parameters $r i$ and $\mathrm{rm}$. To find the input resistance of a parent branch connected to a distal load $R e$, we merely add $X e$ to the length of the parent branch and solve equation (4). We use different versions of equation (4), depending on the value of $R e$. If $R e$ is greater than the infinite cable input resistance $R_{\text {inf }}$ [from equation (2)], then we use equation (4). If $R e$ happens to be equal to $R_{\text {inf }}$, then equation (5) has a singularity and is undefined. In this case, equation (4) reduces to equation (2). If $R c$ is less than $R_{\text {inf }}$, we derive a variation of equation (4) that gives the input resistance $(R o)$ of an open-ended branch (grounded). In this grounded-branch case,

$$
\begin{aligned}
& R o=r i L\left(\frac{e^{x / L}-e^{-x / L}}{e^{x / L}+e^{-x / L}}\right) \\
& X O=\frac{L}{2} \ln \left(\frac{r i \times L+R o}{r i \times L-R o}\right)
\end{aligned}
$$

Thus, for any arbitrary parent branch with a resistance $R e$ at its distal end, we can find its input resistance $R$ by merely adding to the parent the effective length $\mathrm{Xe}$ of an equal-diameter branch that has input re-

Figure 8. Schematic of rod-cone circuit showing spread of rod signal under the 3 conditions modeled $(A-C)$. Left, White arrows show sprcad of current down rod axon to neighboring cells though gap junctions. Right, Tangential view at the level of inner segment (as in Fig. 2). Rods are 20 times more numerous than cones. Each rod diverges to 2-3 cones, and 48 rods converge on each cone. Cone-cone connections are omitted, but were included in the model. $A$, High scotopic intensity $\left(10^{2}\right.$ quanta $\left.\mu \mathrm{m}^{-2} \mathrm{sec}^{-1}\right)$. All rods within illuminated area are continuously activated (*) and therefore approximately isopotential. Signal current does not diverge widely and voltage is near $70 \%$ at both rod spherule and cone pedicle. $B$, Low scotopic intensity $\left(10^{-2}\right.$ quanta $\left.\mu \mathrm{m}^{-2} \mathrm{sec}^{-1}\right)$. Only 1 rod is activated; therefore signal current spreads passively throughout circuit. Gap junctions pass current from rod spherule to cone pedicles, causing voltage decrement to $10 \%$ at spherule. Signal diverges widely throughout cone system, causing voltage decrement to $0.2 \%$ in neighboring cones. $C$, Same as $B$, except that gap junctions are closed. Current from transduction of a single photon is conserved and signal is $86 \%$ at rod spherule. This provides the strongest signal for transmission at chemical synapse between rod spherule and rod bipolar. 


\section{Parameters:}

\begin{tabular}{|c|c|}
\hline Electrical: & $\begin{aligned} \mathrm{Rm} & =5000 \mathrm{Ohm}-\mathrm{cr} \\
\mathrm{Ri} & =100 \mathrm{Ohm}-\mathrm{cm} \\
\mathrm{Rgj} & =5 \times 10^{6} \mathrm{Ohm}-\end{aligned}$ \\
\hline Anatomical: & $\begin{array}{c}1 \text { rod } \rightarrow 3 \text { cones } \\
48 \text { rods } \rightarrow 1 \text { cone } \\
1 \text { cone } \rightarrow 7 \text { cones }\end{array}$ \\
\hline
\end{tabular}

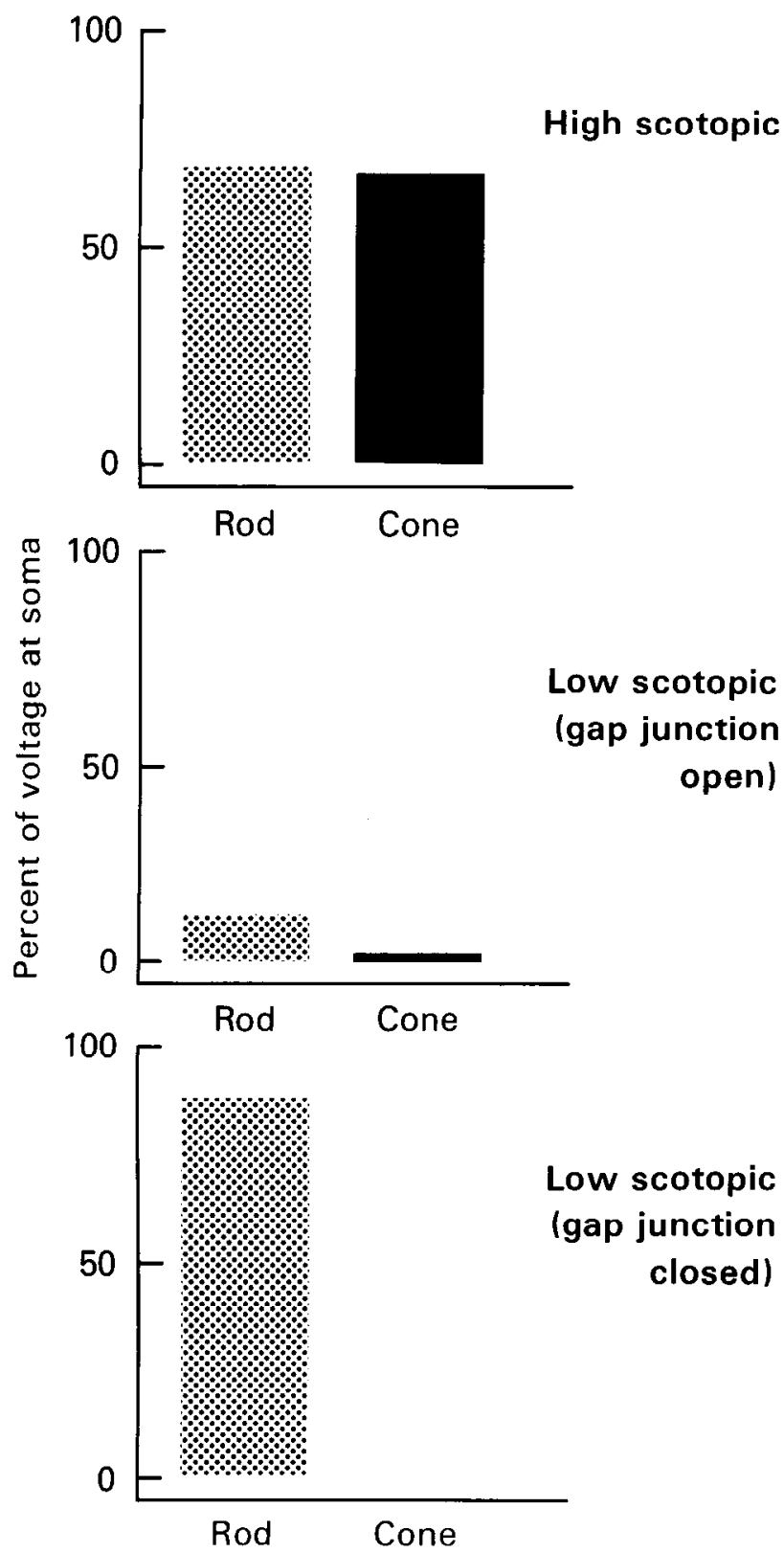

Figure 9. Percentage of soma voltage calculated to appear at rod spherule and cone pedicle for the 3 conditions. Standard parameters were used in the calculation. Top, At high scotopic intensity, collective rod signal is efficiently transferred to cones. Center, At low scotopic intensity, rod signal is reduced in rod terminal and insignificant in cones. Botlom, Low scotopic intensity as in $B$, but with gap junctions closed. Signal in rod terminal is robust. These simulations were repeated for different values of key parameters with essentially the same result (Table 1). sistance equal to $R e$. We use this "extra" segment for conceptual purposes to find the parent's input resistance only, and its diameter is obviously not necessarily equal to the diameter of any descendant branches that, together, comprise the loading resistance $R e$ on the parent branch (see Fig. 10).

If $R e$ is greater than the infinite cable input resistance, we use equation (4) to find the input resistance $R$ of a parent hranch:

$$
R c=r i L\left(\frac{e^{(x+x) / L}+e^{-(x+x) / L}}{e^{(x+X) / L}-e^{-(x+X) / L}}\right)
$$

where $X$ is the effective length of a branch that has input resistance $R e$ Rearranging terms,

$$
R c=r i L\left(\frac{e^{x / L} \times e^{2 x / L}+e^{-x / L}}{e^{x / L} \times e^{2 x / L}-e^{-x / L}}\right)
$$

Substituting $X c$ from equation (5),

$$
R c=r i L\left(\frac{A c \times e^{x / L}+e^{-x / L}}{A c \times e^{x / L}-e^{-x / L}}\right)
$$

where $R c=$ resistance of an arbitrary branch of length $x, r i$, and $L$, with a resistive load $\operatorname{Re}$ (greater than the infinite cable resistance) at its distal end.

$$
A c=e^{2 x c / L}=\frac{R e+r i \times L}{R e-r i \times L}
$$

Note that equation (10) is identical to equation (4) except for the additional term $A c$. A similar derivation of $R$ can be calculated for open-end (grounded) branches:

$$
\begin{aligned}
& R o=r i L\left(\frac{A o \times e^{x / L}-e^{x / L}}{A o \times e^{x / L}+e^{-x / L}}\right) \\
& A o=\frac{r i \times L+R e}{r i \times L-R e}
\end{aligned}
$$

The derivations of equations (10) and (11) are analogous to those of Rall (1959) but allow the explicit use of resistances to represent the load of several descendant branches on their parent branch. This is useful in our model, which includes lump series and shunt resistances for gap junctions and somas, respectively. The $A$ parameter in equations (10) and (11) is analogous to Rall's parameter $B$, except that it is defined as an explicit function of the branch's distal load resistance.

It is also possible to derive voltage ratios from Rall's (1959) cable equation in a similar manner. Using equation (3), we divide the voltage on a closed-end cable at length $x$ by the voltage at length $(x+X)$ to get

$$
V R c=\frac{V(x)}{V(x+X)}=\frac{e^{x / L}+e^{-x / L}}{e^{(x+X) / L}+e^{-(x+X) / L}}
$$

or

$$
V R c=\frac{A c+1}{A c \times e^{x / L}+e^{-x / L}}
$$

where

$$
A c=e^{2 x c / L}=\frac{R e+r i \times L}{R e-r i \times L} \quad \text { [as for equation (10)] }
$$

The voltage ratio can be calculated similarly for an open-end dendrite:

$$
V r o=\frac{A o-1}{A o \times e^{x / L}-e^{-x / L}}
$$

where

$$
A o=\frac{r i \times L+R e}{r i \times L-R e} \quad \text { [as for equation (11)] }
$$

We used equations (10), (11) and (2) to find the effective input resistances of all the branches of a tree network, and used equations (13) and (14) to calculate the voltage transfer across each branch segment.

These derivations provided a general, recursive method for calculating the input resistance of any point in a branching tree network. The input resistance of each parent branch was found by recursively finding 
A

B

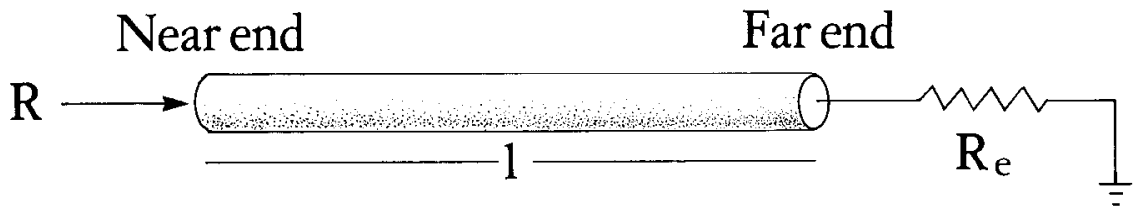

$$
\begin{aligned}
& R=\operatorname{ri} \lambda\left(\frac{e^{x / \lambda} \cdot A+e^{-x / \lambda}}{e^{x / \lambda} \cdot A-e^{-x / \lambda}}\right) \text { where } A=\frac{R_{e}+r i \lambda}{R_{e}-r i \lambda} \\
& \mathrm{R}_{\mathrm{e}}=\text { load on far end of dendrite } \\
& \lambda=\text { electrotonic length of dendrite, }\left(\frac{\mathrm{rm}}{\mathrm{ri}}\right)^{1 / 2}
\end{aligned}
$$

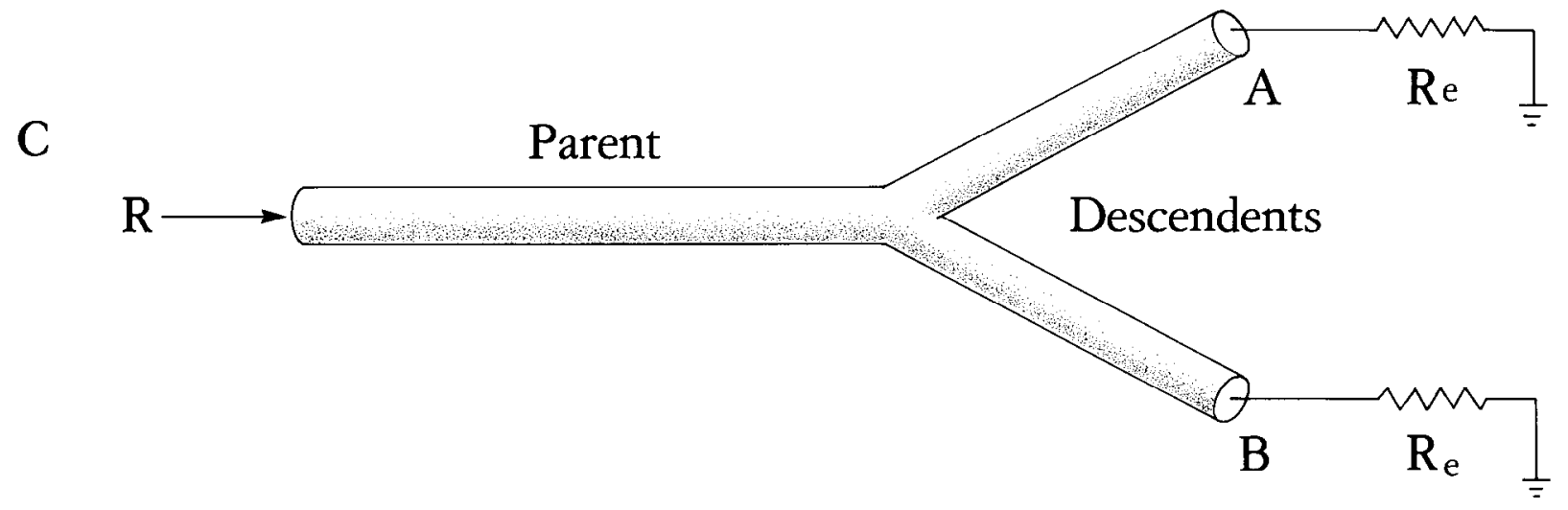

Figure 10. Method used for recursively calculating the input resistance $R$ of the tree circuit. $A$, Each portion of the circuit is characterized as a linear cable $(l)$ with a resistance $(R e)$ loading its distal end. $B$. The input resistance $(R)$ of a circuit fragment is derived directly from standard cable equations. $C$, The next recursion calculates the resistance loading the end of a parent fragment as the parallel combination of the resistances of the descendant fragments. This recursive process is followed until the full extent of the tree circuit has been reached.

the input resistances of its descendant branches, combining their parallel resistances to get the total load of the descendants on the parent, and finally solving for the parent's resistance using the cable equation. The voltage attenuation across the parent branch was also calculatcd from cable equations once the branch's end-load resistance was known. When the voltage attenuations across all the tree branches had been found, the voltage at any point in the tree could be calculated as a function of the voltage at the root. Therefore, using the model, we could assign a voltage to the outer segment of 1 rod and follow its attenuation across each branch in the network. For simplicity's sake, we assumed a voltage source at the rod soma, and measured all other voltages in the network relative to this source voltage. In order to find voltage attenuations from different locations in the cellular network, the tree could be rearranged to define any connection point between cable segments as the root of the tree. Thus, the input resistance of any point in the network could be calculated, and the voltage attenuation between any 2 points could also be found. A similar modeling technique has been derived recently by Koch and Poggio (1985).

\section{Iterative modeling technique}

An iterative technique was used to approximate the properties of the rod-cone network (Fig. 11). We started with a small tree circuit that included only 1 rod and 1 cone, connected through 1 hasal process by a gap junction. The rod spherule and cone pedicle each had an additional "shunt branch" to represent the electrically parallel loading effect of the rest of the basal processes connecting them to other cells. The computer program calculated the input resistance of the basal process (including resistance of gap junction and cone pedicle) looking from the rod spherule.

The program was run again with the same tree except that the input resistance of the shunt branch at the spherule was replaced by the equivalent resistance of 2 basal processes, each having the input resistance just found. Similarly, the shunt load on the cone pedicle was replaced by the parallel resistance of the 47 other basal processes that emanate from the pedicle. After several such iterations, the resistance of the extra loading branches changed no further, but converged to that of an infinite network. This iterative technique allowed a simple schematic model to represent successive surrounding layers of the network elements.

The effect of each additional iteration of this input resistance calculation was to simulate a quantity of cones equal to 3 times the previous number of rods and a quantity of rods equal to 48 times the previous number of cones. It should be noted that in this type of model, there is a constant divergence as a function of radius from the root node of the tree that is not strictly analogous to a 2-dimensional planar network of cells. A planar retinal network, when simulated as a tree network with 1 central current source, has a decreasing divergence with increasing radius. Our model, therefore, predicted a greater attenuation of voltage-several cells from the center-than would exist for the corresponding Bessel function approximation.

To control for the effect of constant divergence, we made several model runs using different anatomical divergence numbers that bracketed the known retinal divergence (see Results). Although this technique did not simulate the properties of the peripheral network well, it was justified by the fact that we were only interested in the properties of the central network elements. Inaccuracies at peripheral elements in the network did not affect the calculations greatly, as is shown by the fact that in most cases no more than 4 iterations were needed for the calculations to converge to 4 decimal places.

\section{Calculating the 2 light-intensity conditions}

The voltage transfer in this network under the low-intensity condition following the transduction of a single photon was calculated using the method just described. At the higher-intensity condition, however, each cone had inputs from multiple rods, while our modeling technique 
A Starting model:

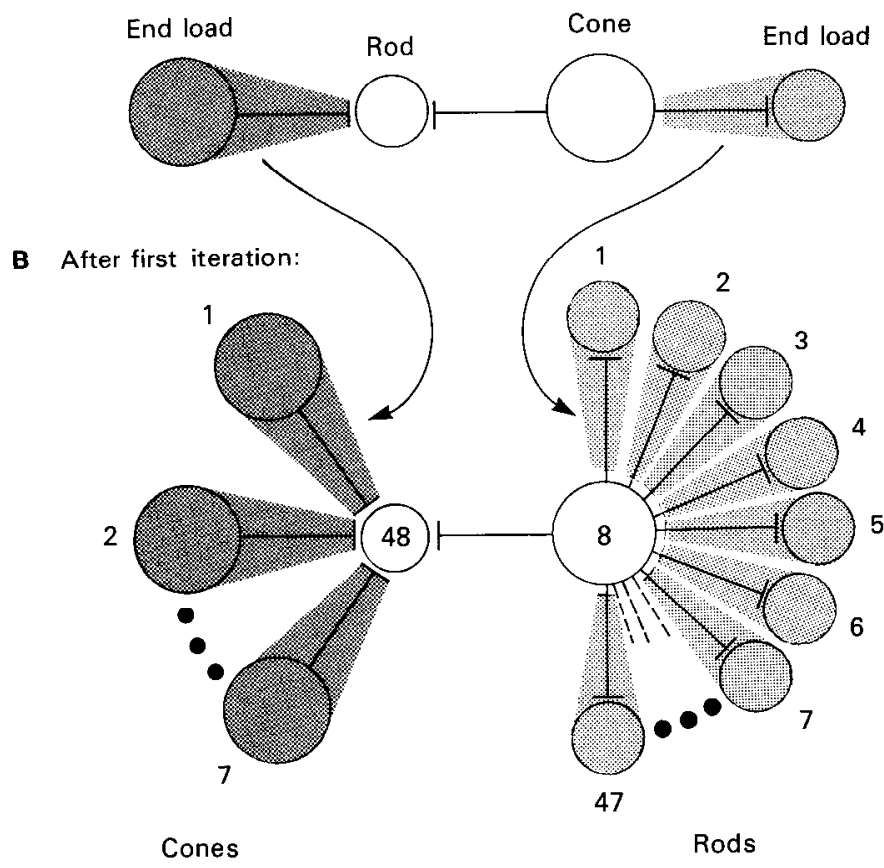

Figure 11. Method of expanding simple circuit to large tree using iterative calculation. $A$, One rod and cone connected by one basal process are placed in larger circuit by modeling the effect of the larger circuit as additional resistive shunt loads. The resistance of the rod looking from the cone, and the resistance of the cone looking from the rod are calculated by the first iteration. $B$, The second iteration replaces the resistive loads seen by both rod and cone with the resistances found from the first iteration for cone and rod, respectively. The effect is to model a tree that expands by 1 order of branching for each iteration. After several iterations, the distal parts of the tree have little effect on the input resistance of the parent rod and cone.

allowed only 1 active voltage source in the circuit. Therefore, we simulated many active rods connected to a cone by treating them as 1 rod with reduced resistance. At higher light intensities, where all rods are simultaneously activated and have similar voltages (Attwell et al., 1984; Schwartz, 1976), a cone would not be loaded by its neighboring cones. This reduction in loading (compared to the single-photon condition) was simulated by increasing the cone-cone coupling resistance by a factor of 100 .

We assumed for the purposes of the model that the quantal signal was a voltage at the rod outer segment. The signal at other parts of the circuit was then defined as a fraction of the input voltage from the rod outer scgment. The results are measured as percentage voltage transfer because the rod signal is destined for voltage-sensitive chemical synapses at the rod and cone terminals.

\section{Static cable model of rod-cone network}

On the basis of the anatomy described above, we made a simplified model of a rod-cone circuit. We omitted the photoreceptor outer and inner segments from the model and assigned a voltage source to the rod soma to represent the driving force (see Materials and Methods). Rods had a small spherical soma ( $3 \mu \mathrm{m}$ diameter), leading to an axon $0.2 \mu \mathrm{m}$ in diameter and $50 \mu \mathrm{m}$ long. Cones had a larger spherical soma $(5 \mu \mathrm{m}$ diameter) and an axon $1.5 \mu \mathrm{m}$ in diameter, also $50 \mu \mathrm{m}$ long. We modeled rod-cone basal processes as cable segments $0.1 \mu \mathrm{m}$ in diameter and 3 $\mu \mathrm{m}$ long, with gap junctions at the end terminating on rods. Cone-cone basal processes have a greater width, about $1 \mu \mathrm{m}$, but are thin, about $0.2 \mu \mathrm{m}$. We modeled these as cable segments of $0.3 \mu \mathrm{m}$ diameter and $3 \mu \mathrm{m}$ long, with terminating gap junctions.

We took the area of a rod-cone gap junction to be $0.02 \mu \mathrm{m}^{2}$ and estimated that it contained about 40 particles (Witkovsky et al., 1983), each of $10^{-10} \mathrm{~S}$ conductance (Loewenstein, 1980; Neyton and Trautman, 1985). This gave an estimate of about $2.4 \times 10^{8} \Omega$ for the resistance of a gap junction in a fully conducting state. Taking the area of the conecone gap junction to be $0.014 \mu \mathrm{m}^{2}$ in area, we calculated a resistance of $3.6 \times 10^{8} \Omega$ for the cone-cone gap junction, using the same estimate of gap junction conductivity as above. For simplicity, we assumed that gap junctions had linear ohmic resistance (Fain, 1975).

\section{References}

Ashmore, J. F., and D. R. Copenhagen (1983) An analysis of transmission from cones to hyperpolarizing bipolar cells in the retina of the turtle. J. Physiol. (Lond.) 340: 569-597.

Ashmore, J. F., and G. Falk (1980) The single-photon signal in rod bipolar cells of the dogfish retina. J. Physiol. (Lond.) 300: 151-166.

Attwell, D., M. Wilson, and S. M. Wu (1984) A quantitative analysis of interactions between photoreceptors in the salamander (Ambystoma) retina. J. Physiol. (Lond.) 352: 703-737.

Barlow, H. B., and W. R. Levick (1969) Three factors limiting the reliable detection of light by retinal ganglion cells of the cat. J. Physiol. (Lond.) 200: 1-24.

Baylor, D. A., T. D. Lamb, and K.-W. Yau (1979) Responses of retinal rods to single photons. J. Physiol. (Lond.) 288: 613-634.

Baylor, D. A., G. Matthews, and K.-W. Yau (1980) Two components of electrical dark noise in toad retinal rod outer segments. J. Physiol. (Lond.) 309: 591-621.

Baylor, D. A., B. J. Nunn, and J. L. Schnapf (1984) The photocurrent, noise and spectral sensitivity of rods of the monkey Macaca fascicularis. J. Physiol. (Lond.) 357: 575-607.

Bonds, A. B., and D. I. A. MacLeod (1974) The bleaching and regeneration of rhodopsin in the cat. J. Physiol. (Lond.) 242: 237-253.

Boycott, B. B., and H. Kolb (1973) The connections between the bipolar cells and photoreceptors in the retina of the domestic cat. J. Comp. Neurol. 148: 91-114.

Coleman, P. A., and R. F. Miller (1984) The electroanatomy of the rabbit on-off amacrine cell. Soc. Neurosci. Abstr. 10: 325.

Detwiler, P. B., and A. L. Hodgkin (1979) Electrical coupling between cones in turtle retina. J. Physiol. (Lond.) 291: 75-100.

Enroth-Cugell, C., B. G. Hertz, and P. Lennie (1977) Cone signals in the cat's retina. J. Physiol. (Lond.) 269: 273-296.

Fain, G. L. (1975) Quantum sensitivity of rods in the toad retina. Science 187: 838-841.

Fain, G. L., and J. E. Lisman (1981) Membrane conductances of photoreceptors. Prog. Biophys. Molec. Biol. 37: 91-147.

Hagins, W. A., R. D. Penn, and S. Yoshikami (1970) Dark current and photocurrent in retinal rods. Biophys. J. 10:380-412.

Holländer, H., and J. Stone (1972) Receptor pedicle density in the cat's retina. Brain Res. 42: 497-502.

Jack, J. J. B., D. Noble, and R. W. Tsien (1983) Electric Current Flow in Excitable Cells, chaps. 5 and 7, Clarendon Press, Oxford, UK.

Koch, C., and T. Poggio (1985) A simple algorithm for solving the cable equation in dendritic trees of arbitrary geometry. $J$. Neurosci. Methods 12: 303-315.

Kolb, H. (1977) The organization of the outer plexiform layer in the retina of the cat: Electron microscopic observations. J. Neurocytol. 6: $131-153$.

Kolb, H., and E. V. Famiglietti (1974) Rod and cone pathways in the inner plexiform layer of cat retina. Science 186: 47-49.

Kolb, H., and R. Nelson (1983) Rod pathways in the retina of the cat. Vision Res. 23: 301-312.

Lamb, T. D., and E. J. Simon (1976) The relation between intercellular coupling and electrical noise in turtle photoreceptors. J. Physiol. (Lond.) 263: 257-286.

Lasater, E. M., and J. E. Dowling (1985) Dopamine decreases conductance of the electrical junctions between cultured retinal horizontal cells. Proc. Natl. Acad. Sci. USA 82: 3025-3029.

Loewenstein, W. R. (1980) Cell to cell communication: Permeability, formation, genetics and functions of the cell-cell membrane channel. In Membrane Physiology, 2nd Ed., T. E. Andreoli, J. F. Hoffman, and D. D. Fanestil, eds., Plenum, New York.

Nelson, R. (1977) Cat cones have rod input: A comparison of response properties of cones and horizontal cell bodies in the retina of the cat. J. Comp. Neurol. 172: 109-136.

Nelson, R. (1982) AII amacrine cells quicken time course of rod signals in the cat retina. J. Neurophysiol. 47: 928-947.

Nelson, R., and H. Kolb (1983) Synaptic patterns and response properties of bipolar and ganglion cells in the cat retina. Vision Res. 23. 1183-1195. 
Nelson, R., and H. Kolb (1985) A17: A broad field amacrine cell in the rod system of the cat retina. J. Neurophysiol. 54: 592-614.

Neyton, J., and A. Trautman (1985) Single-channel currents of an intercellular junction. Nature 317: 331-335.

Peachey, L. D. (1958) Thin sections: A study of section thickness and physical distortion produced during microtomy. J. Biophys. Biochem. Cytol. 4: 233-242.

Penn, R. D., and W. A. Hagins (1972) Kinetics of the photocurrent of retinal rods. Biophys. J. 12: 1073-1094.

Piccolino, M., J. Neyton, and H. M. Gerschenfeld (1984) Decrease of gap junction permeability induced by dopamine and cyclic adenosine $3^{\prime}: 5^{\prime}$-monophosphate in horizontal cells of turtle retina. J. Neurosci. 4: $2477-2488$.

Rall, W. (1959) Branching dendritic trees and motoneuron membrane resistivity. Exp. Neurol. 1: 491-527.

Ramón y Cajal, S. (1892) La retine des vertebres. In La Cellule, Vol. 9, pp. 119-257 [The Structure of the Retina, S. A. Thorpe and M. Glickstein, eds., trans., Thomas, Springfield, IL].

Raviola, E., and N. B. Gilula (1975) Intramembrane organization of specialized contacts in the outer plexiform layer of the retina. A freezefracture study in monkeys and rabbits. J. Cell Biol. 65: 192-222.

Rose, A. (1948) The sensitivity performance of the human eye on an absolute scale. J. Opt. Soc. Am. 38: 196-208.

Schwart7, E. A. (1976) Electrical properties of the rod syncytium in the retina of the turtle. J. Physiol. (Lond.) 257: 379-406.

Schwartz, E. A. (1977) Voltage noise observed in rods of the turtle retina. J. Physiol. (Lond.) 272: 217-246.

Shapley, R. M., and C. Enroth-Cugell (1984) Visual adaptation and retinal gain controls. In Progress in Retinal Research, Vol. 3, pp. 263346, Pergamon, Oxford, UK.

Steinberg, R. H. (1969) The rod after-effect in S-potentials from the cat retina. Vision Res. 9: 1345-1355.
Steinberg, R. H. (1971) Incremental responses to light recorded from pigment epithelial cells and horizontal cells of the cat retina. J. Physiol. (Lond.) 217: 93-110.

Steinberg, R. H., and R. Schmidt (1970) Identification of horizontal cells as S-potential generators in the cat retina by intracellular injections. Vision Res. 10: 817-820.

Steinberg, R. H., R. H. Reid, and P. L. Lacy (1973) The distribution of rods and cones in the retina of the cat (Felis domesticus). J. Comp. Neurol. 148: 229-248.

Sterling, P. (1983) Microcircuitry of the cat retina. Annu. Rev. Neurosci. 6: $149-185$.

Sterling, P., M. A. Freed, and R. G. Smith. (1986) Microcircuitry and functional architecture of the cat retina. Trends Neurosci. 9: 186192.

Stern, J. H., and P. R. MacLeish (1985) Isolated pairs of rod photoreceptors are electrically coupled by a large, voltage-dependent junctional conductance. Invest. Ophthalmol. [Suppl.] 26: 193.

Stevens, J. K., B. A. McGuire, and P. Sterling (1980) Toward a functional architecture of the retina: Serial reconstruction of adjacent ganglion cells. Science 207: 317-319.

Teranishi, T., K. Negishi, and K. Sato (1984) Regulatory effect of dopamine on spatial properties of horizontal cells of carp retina. J. Neurosci. 4: 1271-1280.

Wässle, H., and H. J. Riemann (1978) The mosaic of nerve cells in the mammalian retina. Proc. R. Soc. Lond. [Biol.] 200: 441-461.

Witkovsky, P., W. G. Owen, and M. Woodworth (1983) Gap junctions among the perikarya, dendrites, and axon terminals of the luminositytype horizontal cell of the turtle retina. J. Comp. Neurol. 216: 359368. 